\title{
ANÁLISE DA ECONOMIA DO BRASIL - COMPREENDENDO O PASSADO PARA ENTENDER OS DIAS ATUAIS
}

\section{ANALYSIS OF THE ECONOMY OF BRAZIL - UNDERSTANDING THE PAST TO UNDERSTAND CURRENT DAYS}

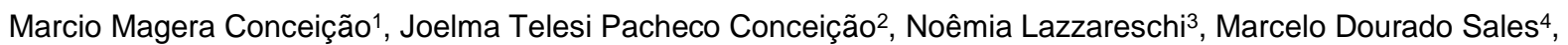
Maurício Lamano Ferreira ${ }^{5}$

\author{
Submetido em: 01/04/2021 \\ Aprovado em: 23/04/2021
}

\section{RESUMO}

Este artigo descreve a trajetória política, econômica e social do Brasil colônia até o século XXI. Não existe aqui a pretensão de entrar nos detalhes, apenas ressaltar os fatos históricos e econômicos importantes para o leitor compreender dentro do contexto da época, as ações tomadas pelos agentes políticos e sociais que levaram ao quadro socioeconômico dos dias atuais. Apresentando seus ciclos econômicos e a geopolítica adotada pelos portugueses, durante quase quatro séculos de domínio, colocará recursos adequados para a compreensão das reais condições e o contexto da época para o retrato atual do Brasil. Entender como foi esta dinâmica e o papel dos seus atores levará o leitor a compreender por que o Brasil ainda é uma nação em desenvolvimento e com graves problemas sociais. $\mathrm{O}$ fato de, ainda no século $\mathrm{XXI}$, o Brasil não ter encontrado seu caminho ao desenvolvimento sustentável, tem relação intrínseca com seu passado e o comportamento de suas elites. O déficit público chegando a $90 \%$ do PIB, levará o Brasil a ter que lidar com taxas de juros em alta e inflação a médio prazo. Essas questões, mais a antecipação do debate das eleições de 2022, tem levado o país a consumir suas reservas internacionais para manter o câmbio e a tomar medidas restritivas ao seu desenvolvimento. Não haverá saída, sem um ajuste nas contas públicas, com cortes de até $20 \%$ dos gastos correntes e a diminuição do tamanho do Estado brasileiro e isto, passa pela aprovação do Congresso Nacional. Este mesmo Congresso representado por uma elite

\footnotetext{
1 Economista pela PUC- Campinas. MBA de Marketing pela ESAMC, Sorocaba. Mestrado em Administração pela UNG - Guarulhos. Mestrado em Sociologia pela PUC - São Paulo. Doutor em Sociologia pela PUC - São Paulo. Doutor em Filosofia da Administração pela FCU - EUA, diploma Reconhecido no Brasil pela Universidade UNAMA, Pará. Pós-Doutor Unicamp - Campinas. Pós-Doutor FCU - EUA. Pós-Doutor Universidade de CoimbraPortugal. Jornalista e Escritor. Avaliador do MEC/INEP, há 16 anos. Pró-Reitor da Universidade Guarulhos, SP. Pesquisador do grupo de cientistas da Centro de Ecologia Funcional da Universidade de Coimbra, Portugal. Pesquisador da Universidade Paulista, UNIP. Professor do programa de mestrado Geoambiental da Universidade Guarulhos. Editor chefe da RECIMA21.

2 Mestrado em Administração de Empresas, nos últimos oito anos ministrei aulas em graduação e pósgraduação, dominando diversas disciplinas em cursos de Administração e Tecnológicos em Gestão de Recursos Humanos, Logística, Comércio Exterior, Gestão da Qualidade, Gestão Comercial, entre outros. Orientei a elaboração de trabalhos de conclusão de cursos (TCC) em graduação e pós-graduação. Trabalhei durante treze anos na educação infantil e acredito que esta experiência sirva de diferencial para um relacionamento didático e criativo com os alunos universitários.

${ }^{3}$ Mestrado em Sciences Sociales Du Travail - Université Catholique de Louvain (1971) e doutorado em Ciências Sociais pela Universidade Estadual de Campinas (1995). Atualmente é assistente doutor da Pontifícia Universidade Católica de São Paulo. Tem experiência na área de Sociologia, com ênfase em Sociologia do Trabalho, atuando principalmente nos seguintes temas: trabalho, turismo, reestruturação produtiva, emprego e tempo livre.

4 Profissional de Coaching Executivo e Mentoria para Executivos, especialista para área de arquitetura, consultor para empreendedores e médias empresas para gestão de processos, pessoas, performance e projetos. Palestrante e Facilitador de Workshops para a área de T\&D. Docente com oito anos de experiência na Graduação, Tecnólogos e Pós-Graduação. Professor universitário e tradutor com doutorado na FCU.

5 Pós-doutor pela Universidade de São Paulo (CENA/USP), Doutor em Ciências pela Universidade de São Paulo (CENA/USP), Mestre em Biodiversidade Vegetal e Meio Ambiente pelo Instituto de Botânica de São Paulo (IBT/SP), formado em Geociências pelo Instituto de Geociências da USP (IGc/USP) e também em Ciências Biológicas pela Universidade Mackenzie (UPM).
} 


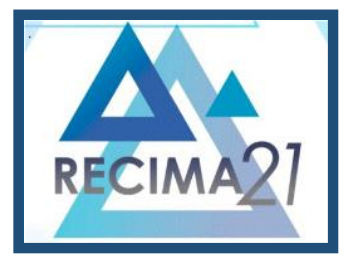

\section{RECIMA21 - REVISTA CIENTÍFICA MULTIDISCIPLINAR}

carcomida, cujo objetivos são individuais e não republicanos. A nação brasileira ainda não se encontrou com o século XXI.

PALAVRAS-CHAVE: Economia. Colônia. Corrupção. Déficit público. Inflação. Subdesenvolvimento. Política

\section{ABSTRACT}

This article describes the political, economic and social trajectory of colony Brazil up to the 21st century. There is no intention here to go into the details, just to highlight the historical and economic facts important for the reader to understand, within the context of the time, the actions taken by the political and social agents that led to the current socioeconomic situation. Presenting its economic cycles and the geopolitics adopted by the Portuguese during almost four centuries of domination, it will provide adequate resources for understanding the real conditions and the context of the time for the current portrait of Brazil. Understanding this dynamic and the role of its actors will lead the reader to understand why Brazil is still a developing nation with serious social problems. The fact that, even in the 21st century, Brazil has not found its way to sustainable development has an intrinsic relationship with its past and the behavior of its elites. The public deficit, reaching $90 \%$ of GDP, will lead Brazil to deal with rising interest rates and inflation in the medium term. These issues, plus the anticipation of the 2022 elections, have led the country to consume its international reserves to maintain the exchange rate and to take restrictive measures to its development. There will be no way out, without an adjustment in public accounts, with cuts of up to $20 \%$ in current spending and a decrease in the size of the Brazilian state, and this requires approval by the National Congress. This same Congress represented by an eaten elite, whose objectives are individual and not republican. The Brazilian nation has not yet met the 21st century.

KEYWORDS: Economy. Colony. Corruption. Public deficit. Inflation. Public deficit. politics

\section{INTRODUÇÃO}

Entender a economia do Brasil, necessariamente leva o leitor a precisar compreender seu passado como colônia, império e anos de turbulências políticas registrados no século XX. Fruto da expansão marítima europeia do século $\mathrm{XVI}$, o descobrimento do Brasil se dá por um acidente de percurso, visto que as Caravelas de Cabral estavam indo para as Índias, atrás de especiarias e não necessariamente querendo encontrar um novo continente, como retrata Eduardo Bueno, "A armada de Cabral, ancorada em frente ao Restelo, com seus cordames rangendo a saudosa balada das partidas, estava constituída por duas divisões. A primeira, composta por cinco naus, duas caravelas, uma capitânia e da sota-capitânia, partiria para Calicute, na Índia, com a missão de estabelecer relações comerciais com o Samorim e fundar uma feitoria" (1998, pag. 22).

A partir do seu descobrimento, o Brasil passou a ser uma colônia de exploração e toda a sua riqueza acabou indo para a Europa, via Portugal. Suas árvores, índios, ouro e pedras preciosas, bem como todo o seu excedente dos ciclos de desenvolvimento econômico, foram usados pelos portugueses para financiar suas guerras, invasões e sua saga expansionista pelo mundo, durante os séculos, XVI, XVII e XVIII. Mesmo os ciclos econômicos aqui registrados, tais como o ciclo da cana de açúcar, o ciclo do ouro, café e da borracha, este último no século $X X$, não trouxeram um 


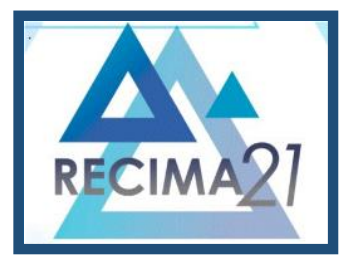

\section{RECIMA21 - REVISTA CIENTÍFICA MULTIDISCIPLINAR}

ANÁLISE DA ECONOMIA DO BRASIL - COMPREENDENDO O PASSADO PARA ENTENDER OS DIAS ATUAIS Marcio Magera Conceição, Joelma Telesi Pacheco Conceição, Noêmia Lazzareschi, desenvolvimento econômico e social esperado para nosso país. O Brasil entrou no século XX como um país rural e subdesenvolvido, competindo sua pobreza com seus vizinhos da América Latina. Fatos relatados no livro "As veias Abertas da América Latina", escrito por Eduardo Galeano.

Com a proclamação da república em 15 de novembro de 1889, o Brasil passou a ter uma Constituição republicana e não mais imperialista e novos agentes políticos assumiram o protagonismo da gestão pública. Muito havia por fazer, mas as elites conservadoras e ainda retrógadas do tempo do império, não deixavam as reformas políticas irem adiante, e o Brasil ficou na alternância entre governos representados pelo Estado de São Paulo e Minas Gerais, a política conhecida como "café com leite". Entretanto, em 1930, Getúlio Vargas, assumiu o poder com um golpe de Estado, e governou até 1945, voltou eleito em 1950, quando em 24 de agosto de 1954, deu um tiro em seu próprio peito, descrevendo em seu testamento: "saio da vida para entrar na história", (FAUSTO, 2006).

Após a Segunda Grande Guerra mundial, o Brasil se alinhou politicamente aos Estados Unidos e o governo de Juscelino Kubitschek atraiu investimentos para nosso país. Governou o país entre 1956-1961. Mas, com a saída de Juscelino e a renúncia de Jânio Quadros (1961), que o sucedeu no governo federal, o país passou novamente por turbulências políticas, o que levou ao golpe militar de 1964. Ficando 20 anos no poder, os militares deixaram um país melhor do que encontraram, social e economicamente. A média de crescimento na década de 70 era de 7 a $8 \%$ do PIB, com grande expansão monetária e infraestrutura (VELOSO, 2008). Segundo o FMI -Fundo Monetário Internacional, foi o país que mais cresceu no mundo. Entretanto, este crescimento econômico não trouxe uma distribuição de renda mais equânime.

Com a saída dos militares, o país passou por um processo de redemocratização, com a volta das eleições gerais livres, ocasionando uma ruptura com o modelo até então instalado. Neste contexto, o Congresso Nacional aprovou uma nova Constituição, a Constituição Cidadã de 1988. Com um viés ideológico e estatizante, as novas Leis pétreas trouxeram um atraso para o país. O que se viu então foram muitas contradições e corrupção generalizada por todo o território nacional, o que será retratado nos próximos capítulos deste artigo.

\section{DA ECONOMIA COLONIAL AO SÉCULO XX - OS CICLOS DA EXPLORAÇÃO E CONCENTRAÇÃO DA RENDA}

Para entender os dias atuais, o leitor precisa passar por uma contextualização histórica do nosso país. Compreender o passado implica em ter a capacidade de realizar uma leitura do cenário atual sem partidarismo ou parcialidade no texto. A história do Brasil representa um legado do seu povo com seu imenso território, e como seu desenvolvimento econômico sempre dependeu de fatores externos, e as vezes, por uma regência internacional. 


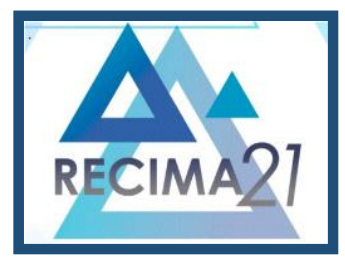

\section{RECIMA21 - REVISTA CIENTÍFICA MULTIDISCIPLINAR}

ANÁLISE DA ECONOMIA DO BRASIL - COMPREENDENDO O PASSADO PARA ENTENDER OS DIAS ATUAIS Marcio Magera Conceição, Joelma Telesi Pacheco Conceição, Noêmia Lazzareschi,

No princípio do período colonial, durante o século XVI, o Brasil não era considerado algo valioso pela coroa portuguesa. Embora o território adquirido fosse imenso, não trouxe a esperada sorte econômica obtida pelos espanhóis em suas conquistas no Peru e México. O território brasileiro era esparsamente habitado por Índios nômades, algo em torno de 4 milhões, e não se adaptavam facilmente à disciplina e ao trabalho na agricultura. Mesmo assim, isto não impediu o país de começar sua imersão econômica no cenário internacional no século $\mathrm{XVI}$, quando os portugueses começaram a comercializar o pau-brasil. O pau-brasil é uma árvore típica da Mata Atlântica. A árvore ganhou importância para os portugueses por conta da sua madeira, que poderia ser utilizada na construção de inúmeros objetos, mas principalmente, porque a resina da madeira era utilizada para produzir corante para tingir tecidos (Brasil-escola, 2021).

A segunda e não mais importante, foi a comercialização dos índios como mão de obra escrava para a Europa. Mas isto não deu certo, os índios não suportavam a viagem de quase 2 meses pelo oceano Atlântico e o negócio de tráfico de índios não perdurou. Nesta toada de expansão, chegou o ciclo da cana de açúcar que perdurou do século XVI até o XVIII, sem dúvida, a atividade econômica mais consistente do Brasil Colônia. Esta cultura foi extremamente importante, uma vez que estimulou o povoamento da colônia e a ocupação de seu território, que até então só margeava o litoral.

Quando este segundo ciclo econômico entra em decadência, aparece o café. O ciclo do café no Brasil teve seu começo em 1727, início do século XVIII, quando chegaram ao país as primeiras mudas. Durante muito tempo o produto foi plantado para consumo interno. A cultura em pequenas proporções no norte do país foi se expandindo em direção ao sudeste quando, no final do século XIX, teve seu apogeu, no interior do Estado de São Paulo, onde encontrou um solo propício para os cafezais e mão de obra escrava e algumas qualificadas dos imigrantes italianos. As fazendas se espalharam, a produção exportadora cresceu, e tivemos o registro de novos imigrantes que vieram trabalhar nas fazendas. Mais tarde, com o trabalho livre e o início da mecanização, os fazendeiros diversificaram suas atividades, investindo no comércio e na indústria de bens de consumo. A ferrovia teve um papel importante neste período, contribuindo com a logística e com o desenvolvimento populacional do interior do país (CONCEIÇÃO, 2006).

Compartilhando quase no mesmo tempo histórico com o café, chega o ciclo do ouro, é a época em que a extração e exportação do ouro figurava como principal atividade econômica no período colonial. Teve seu início no final do século XVII, momento em que as exportações do açúcar nordestino caíam pela concorrência exercida pela produção açucareira de ingleses e holandeses no Caribe. Bem como a cana de açúcar e o café, o ciclo do ouro provocou mudanças na ocupação do território nacional, e trouxe novos visitantes a Colônia (FURTADO, 1977).

Começou a se formar a elite brasileira e suas reais necessidades de consumo, o que se contrapunha aos interesses de Portugal, que via no Brasil apenas um local de exploração e não de produção industrial. A fim de garantir o controle sobre a extração e envio do ouro, a Coroa instituiu vários impostos e transferiu no ano de 1763, a capital do Brasil de Salvador para o Rio de Janeiro. 


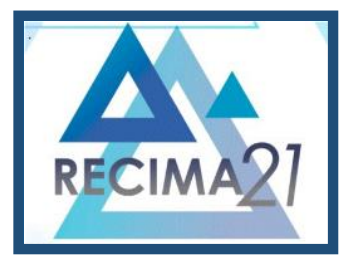

\section{RECIMA21 - REVISTA CIENTÍFICA MULTIDISCIPLINAR}

ANÁLISE DA ECONOMIA DO BRASIL - COMPREENDENDO O PASSADO PARA ENTENDER OS DIAS ATUAIS Marcio Magera Conceição, Joelma Telesi Pacheco Conceição, Noêmia Lazzareschi,

Entretanto, em meados do século XVIII, Portugal atravessava dificuldades econômicas decorrentes da sua gestão administrativa, voltada para a mão de obra escrava e a centralização do poder político de grande extensão colonial. Nesse período, o país sofria também pressão da Inglaterra, a qual, ao se industrializar, buscava consolidar seu mercado consumidor, bem como sua hegemonia mundial. $O$ mercado procurava consumidor com renda, mas o escravo não tinha renda e nem salário, o que dificultava o plano de expansão geopolítica da Inglaterra.

O ciclo da borracha teve seu início no final do século XIX e início do XX. O ciclo da borracha foi um momento da história econômica e social do Brasil, relacionado com a extração de látex da seringueira, e sua comercialização foi responsável pelo desenvolvimento da região Amazônica. Neste período o Brasil já era independente de Portugal e começava a escrever sua própria história econômica e política.

Neste contexto, de quase 4 séculos de domínio português, que se pode descrever como: 322 anos como colônia e 67 anos de império, sem um plano de desenvolvimento econômico e sem garantias de um território nação, o Brasil chegou ao século XX como uma nação atrasada em relação aos seus vizinhos da América do Sul, principalmente a Argentina, Venezuela e Chile. Tendo vários ciclos econômicos, pau-brasil, cana de açúcar, café, ouro e borracha, o país chegou no século XX como uma republiqueta de bananas, expressão criada pelo escritor americano William Sydney Porter, no conto O Almirante, de 1904, que se referia às repúblicas latino-americanas de uma forma pejorativa. Assim, tem-se um imenso território e uma população sem uma identidade definida (RIBEIRO,1997), politicamente instável e submisso a uma nação rica.

A economia nacional não conseguiu reter o excedente gerado pelos ciclos econômicos dos séculos passados, sendo assim, a nação figura-se como uma das mais pobres da América Latina no início do século $X X$, apesar de toda a riqueza de seu território. É um grande país rural, tendo boa parte da sua população vivendo no campo, as cidades neste início do século $X X$ não tinham grande destaque no cenário político/geográfico, (SALGADO, 1978).

\section{A INDUSTRIALIZAÇÃO}

O período de industrialização brasileira surgiu em uma época de crise, na qual o capitalismo mundial, por volta de 1873/1896, punha fim à etapa concorrencial e iniciava a etapa monopolista de capital. Segundo João Manoel Cardoso de Mello, o Brasil registrou seu crescimento econômico restringido na década de 30. Período este que se instalavam os três departamentos na economia, o DI, DII e DIII - DI, bens de consumo de capital, DII, bens de consumo dos capitalistas e DIII, bens de consumo dos trabalhadores. Mas, pelo seu passado colonial, e por ter sido um território de exploração e não de expansão, como foi os Estados Unidos, o país não criou uma distribuição de riqueza adequada, uma poupança interna e nem formou uma nação com cultura para atender os seus cidadãos com formação educacional, visto que muito pouco era investido nesta área. 


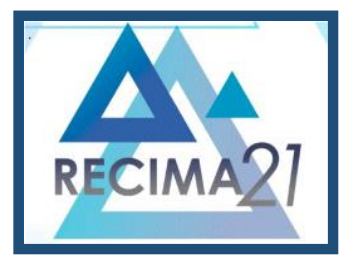

\section{RECIMA21 - REVISTA CIENTÍFICA MULTIDISCIPLINAR}

ANÁLISE DA ECONOMIA DO BRASIL - COMPREENDENDO O PASSADO PARA ENTENDER OS DIAS ATUAIS Marcio Magera Conceição, Joelma Telesi Pacheco Conceição, Noêmia Lazzareschi,

As famílias ricas, de posse, enviavam seus filhos para estudarem no exterior. Tendo as elites uma alternativa às suas necessidades, os gestores públicos não tinham interesses em iniciar uma política educacional para todos do território nacional. Algumas cidades apenas tinham seus colégios e poucos brasileiros tinham acesso à escola. As famílias usavam seus filhos para a lavoura e trabalhos domésticos, deixando a escola somente para os filhos das elites constituídas pelos ciclos econômicos passados.

Nunca houve, por parte das elites, interesse em criar no país centros educacionais que levassem o povo a aprender a ler e escrever. $O$ trabalho existente na época não necessitava que seu executor soubesse ler ou escrever. A única habilidade exigida era possuir força física e saber aplicála. Foi no início do século XIX, com a mudança da sede do Reino de Portugal e a vinda da família Real para o Brasil-Colônia, que a educação e a cultura tomaram um novo impulso, com o surgimento de instituições culturais e científicas, de ensino técnico e dos primeiros cursos superiores, como os de medicina nos estados do Rio de Janeiro e da Bahia. Ou seja, depois de mais de 300 anos da sua descoberta, o Brasil começou a escrever sua educação pelas suas próprias mãos.

Quando do advento da industrialização no início da Era Vargas (1930), o mercado começou a ficar mais seletivo e, com isto, criou-se a necessidade de formar mão de obra mais qualificada. Assim, começamos a ter investimentos mais robustos na área de educação básica, ensino fundamental e médio. Entretanto, as escolas de nível superior e técnico, só intensificaram a partir da década de 60, em pleno regime militar (1964-1985). Neste período registramos a criação de algumas universidades federais e o setor privado também começou a investir neste segmento, mas ainda de forma incipiente. Tivemos de fato um crescimento nesta área somente no final do século XX.

O Brasil iniciou um processo de redemocratização a partir de 1985, com a saída do regime militar e a volta dos civis ao comando da nação. Isto ocorreu sem derramamento de sangue ou conflitos armados. O que levou os militares saírem do poder foi o descontrole da inflação, o desequilíbrio fiscal, a dívida pública chegando a $60 \%$ do PIB e a dívida externa cresceu 32 vezes, saindo de U\$ 3 bilhões de dólares em 1964, para U\$ 105 bilhões de dólares no ano de 1985, o desemprego em massa e a corrupção em alguns órgãos do governo (site, Auditoria, 2021). Entretanto, com os novos governantes vieram também os interesses de alguns grupos pelo poder e controle dos órgãos públicos, e o país começou a registrar um crescimento de registro de partidos políticos, passando de 2 para $33 \mathrm{em}$ pouco tempo. Todos com muitas ideologias, mas pouco patriotismo! Os partidos políticos no Brasil têm "dono" e muitos são usados para interesses individuais e pouco republicano.

O processo de redemocratização trouxe junto dois impeachments - Fernando Collor de Melo (1992) e Dilma Rousseff (2016), bem como, um projeto de poder do Partido dos Trabalhadores que ficou 14 anos governando o Brasil e aparelhou toda a máquina pública (Malu Gaspar, 2021). Com isto, o país que mais cresceu e distribuiu renda entre os anos de 1930 até 1980, caiu em desgraça 


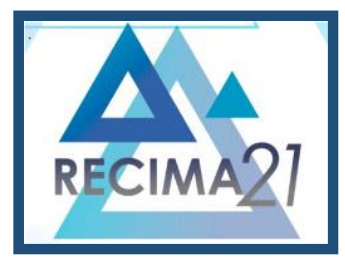

\section{RECIMA21 - REVISTA CIENTÍFICA MULTIDISCIPLINAR}

ANÁLISE DA ECONOMIA DO BRASIL - COMPREENDENDO O PASSADO PARA ENTENDER OS DIAS ATUAIS Marcio Magera Conceição, Joelma Telesi Pacheco Conceição, Noêmia Lazzareschi, profunda, com números sociais e econômicos que assustaram todos os investidores nacionais e internacionais até os dias atuais.

\section{OS DIAS ATUAIS}

O ano de 2020 ficará na história como um grande divisor de águas. De um lado as nações ricas que possuem tecnologia e criaram seus respectivos remédios/vacinas, e de outro, as nações pobres que dependem de tecnologia e, em troca disso, oferecem seus recursos naturais, seus territórios e mão de obra barata, e as vezes até sua própria soberania.

No meio disso tudo, apareceu o Covid-19 - vírus que surgiu no ano de 2019, na cidade de Wuhan na China - que provocou uma pandemia, e as nações registraram quedas em seus crescimentos econômicos e de renda, fruto da retração do consumo das pessoas e o fechamento de vários países. O Covid-19 acabou, na verdade, mostrando as vísceras do sistema público de saúde deficitário de grande parte das nações e o Brasil está entre elas.

Neste cenário de desajuste fiscal entramos no ano de 2021, sem um orçamento aprovado e uma confusão em torno dele, inclusive abrindo uma infinidade de crimes de responsabilidade fiscal, por parte do governo federal. As consequências não demoraram a aparecer: o dólar subindo, a inflação voltando e os juros futuros dispararam. Se mantido este cenário, já se conhece os resultados: cortes de salários e de aposentadorias em mais de 35\%. Não é mais tolerável o Estado custar $40 \%$ do Produto Interno Bruto, enquanto na média dos países emergentes essa relação varia entre $15 \%$ a $25 \%$.

O Brasil nas últimas duas décadas praticamente não cresceu. Enquanto outras nações emergentes registraram crescimentos de $4 \%$ ao ano, ficamos patinando no mesmo lugar, fruto do tamanho da máquina pública brasileira, instabilidade política e jurídica. Este baixo crescimento traz consigo o aumento da pobreza e as desigualdades sociais. Assim, o endividamento público com os pacotes de enfrentamento da pandemia que chegou a $\mathrm{R} \$ 700$ bilhões de reais, ajudou a dívida pública a chegar $90 \%$ do PIB. E o processo de financiamento desta dívida, todos sabemos, mais títulos públicos serão ofertados a uma taxa de juros futuro acima da média dos últimos anos. Estamos 20\% mais pobres e a arrecadação pública vem caindo. O próprio governo já vem sinalizando para o mercado que teremos inflação e desajuste fiscal para os próximos anos.

A antecipação dos debates eleitorais para 2020 e 2021, colocou uma agenda inevitável entre os atores do comando deste processo que são os políticos e empresários. Cada qual, desejando uma fatia do orçamento público deste governo, que já gasta tudo o que arrecada, chegando a $40 \%$ do PIB. Estes atores nunca quiseram resolver os problemas de fato do país. Sempre atuam nos efeitos e nunca nas causas deles. O Estado é maior do que o país, e para manter estas castas de privilegiados, o povo, fica todo ano mais pobre. O serviço público no Brasil é ruim e caro. O governo quer fazer tudo e não faz nada direito. Os gastos públicos aumentaram em mais de 3 vezes deste 1990, nas três esferas, em contrapartida, o povo, o pagador destes impostos, está $50 \%$ sem 


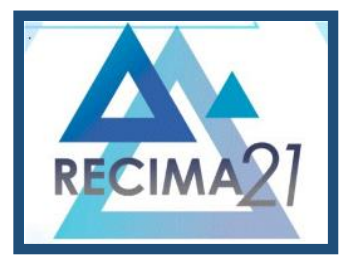

\section{RECIMA21 - REVISTA CIENTÍFICA MULTIDISCIPLINAR}

ANÁLISE DA ECONOMIA DO BRASIL - COMPREENDENDO O PASSADO PARA ENTENDER OS DIAS ATUAIS Marcio Magera Conceição, Joelma Telesi Pacheco Conceição, Noêmia Lazzareschi, saneamento básico, enquanto $30 \%$ dos brasileiros não tem água encanada (IBGE, 2020). Isto tudo é consequência de um Estado inchado e inoperante, sem deixar de lado a corrupção endêmica instalada em todas as esferas municipais, estaduais e federal (Malu Gaspar, 2021). O país passou a ocupar a 106a posição do Índice de Percepção da Corrupção (IPC), o que representa o pior resultado desde 2012. A nota brasileira foi a mesma do ano de 2018, 35 pontos, a pior pontuação da séria histórica, segundo a fonte Transparência Internacional (2021).

O país não apresenta condições financeiras para atrair investidores internacionais e até os investidores nacionais estão fugindo da nossa moeda e apostando contra o Real. Nossa moeda saiu de um câmbio de $R \$ 3,90$ em 2018 para $R \$ 5,7$, este ano, e pode cair ainda mais, segundo analistas financeiros. O Banco Central atua na taxa básica de juros (Selic) e o crescimento depende desta taxa e do cenário político institucional. Em relação à taxa, deve ficar em $5 \%$ até 2022, já as questões políticas, tudo ainda é incerto. Existem deputados que estão pedindo o impeachment do governo, para eles, o objetivo maior sempre será a conquista do poder, as condições sociais do povo e o país estão relegados a segundo plano em suas intenções.

No momento, o país registra uma combinação explosiva: juros em alta, inflação e desemprego chegando a 14 milhões da PEA - População Economicamente Ativa. A política monetária expansionista do governo pode trazer algum alento a este cenário, mas a médio e longo prazo, o aumento dos preços será inexorável. A queda do PIB do ano de 2020 foi de $4,1 \%$ e para este ano a projeção será de um crescimento de 2,5 a $3 \%$ do PIB, se considerarmos os $4,1 \%$ de queda, ainda estamos no negativo em $1,1 \%$ do PIB. E se o comércio e serviços permanecerem em lockdown nos estados e municípios até o final do ano, estes números serão ainda mais negativos.

\section{CONSIDERAÇÕES FINAIS}

Levando-se em consideração os ciclos econômicos e toda a expansão territorial do Brasil no período que vai do século $\mathrm{XVI}$ até o XIX, fica evidente que não houve interesse algum dos portugueses em alavancar um território economicamente sustentável aqui na América do Sul. $O$ Brasil era usado como um quintal de exploração de recursos naturais. Era proibido até a existência de indústria de manufatura em solo brasileiro, tudo isto orquestrado por uma elite europeia carcomida e atrasada.

No advento da república, já no final do século XIX, as elites que assumiram o poder não tinham muito interesse em mudar estruturalmente o país e mesmo com uma nova Constituição, a de 1891, o povo não sentiu grandes mudanças no seu cotidiano. Mudaram apenas os mandatários a miséria continuava sentida na pele dos que construíam este país.

Entramos assim no século XX, com muitos desafios e poucos recursos econômicos para alavancar o país. Mas, na década de 30, rompendo com a política do "café com leite" estabelecida pelos Estados de Minas e São Paulo, surgiu um governo nacionalista, Getúlio Vargas, que posicionou o Brasil no cenário internacional, com a criação de muitas indústrias nacionais: Petrobrás, 


\section{RECIMA21 - REVISTA CIENTÍFICA MULTIDISCIPLINAR}

ANÁLISE DA ECONOMIA DO BRASIL - COMPREENDENDO O PASSADO PARA ENTENDER OS DIAS ATUAIS Marcio Magera Conceição, Joelma Telesi Pacheco Conceição, Noêmia Lazzareschi,

Vale do Rio Doce, Companhia Siderúrgica Nacional, Hidrelétrica do Vale do São Francisco, Fábrica Nacional de Motores, entre outras. Depois de ter ficado mais de 19 anos no poder, em dois momentos, deixou o governo em 1954 de uma forma trágica, e o país voltou a registrar turbulências políticas, o que culminou com o golpe militar de 1964.

O Brasil foi o país que mais cresceu entre 1930 e 1980, a economia brasileira cresceu a uma das taxas mais elevadas do mundo, em média $6 \%$ ao ano, assim, deixou de ser um país predominantemente rural e agrícola para se tornar urbano e com sua produção concentrada na indústria e no setor de serviços. Embora tenha havido uma grande acumulação de capital neste período, não houve uma elevação dos salários e nem uma distribuição de renda aos trabalhadores, que em sua grande maioria, ainda recebem até 2 salários mínimos por mês, segundo o IBGE, 2020.

Analisando os dados atuais da economia brasileira percebe-se que as taxas de juros continuarão subindo, bem como a inflação e o desemprego, acompanhado de perto com o déficit público, que já está em 90\% do PIB. Em 2022, com o advento das eleições para presidente da república, teremos vários candidatos, todos apresentado muitas soluções para os problemas aqui apresentados de ordem estrutural e administrativa. Sem alterar a Constituição de 88, liberando assim ao novo governante promover reformas estruturais, o país não vai alcançar as economias desenvolvidas e ficaremos eternamente no subdesenvolvimento. O que no entender destes autores, e por tudo o que foi dissertado neste artigo, é uma vontade explicita das elites políticas, sindicais, empresariais e eclesiásticas deste rico país, mas sem ainda ter uma nação séria de princípios.

\section{REFERÊNCIAS}

BARROS, R.; FOGUEL, M.; ULYSSEA, G. Desigualdade de Renda no Brasil: uma Análise da Queda Recente. Rio de Janeiro: IPEA, 2007.

BUENO, Eduardo. A Viagem do Descobrimento. Rio de Janeiro: Editora Objetiva, 1998.

CARDOSO, João M. Mello. O capitalismo tardio. São Paulo: Ed. Brasiliense, 1987.

CONCEIÇÃO, Márcio Magera. Meus artigos, minha vida. São Paulo: Editora Otonni, 2006.

FAUSTO, Boris. Getúlio Vargas. Rio de Janeiro: Companhia das Letras, 2006.

FURTADO, Celso. Formação Econômica do Brasil. Rio de Janeiro: Ed. Companhia Nacional, 1977.

GALEANO, Eduardo. As veias abertas da América Latina. Rio de Janeiro: Paz e Terra, 1996.

GASPAR, Malu. A organização: A Odebrecht e o esquema de corrupção que chocou o mundo. Rio de Janeiro: Companhia das Letras, 2021.

LANGONI, C. Distribuição da Renda e Desenvolvimento Econômico do Brasil. 3. ed. Rio de Janeiro: Ed. FGV, 2005.

LEÃO, A, Carneiro. Panorama sociológico do Brasil. Rio de Janeiro: INEP, 1958. 


\section{RECIMA21 - REVISTA CIENTÍFICA MULTIDISCIPLINAR}

ANÁLISE DA ECONOMIA DO BRASIL - COMPREENDENDO O PASSADO PARA ENTENDER OS DIAS ATUAIS Marcio Magera Conceição, Joelma Telesi Pacheco Conceição, Noêmia Lazzareschi,

RIBEIRO, Darci. O povo brasileiro. Rio de Janeiro: Editora Companhia das letras, 1997.

SALGADO, Plinio. Como nasceram as cidades do Brasil. São Paulo: Editora Voz do Oeste, 1978.

SIMONSEN, M. H.; CAMPOS, R. "A Nova Economia Brasileira”. Rio de Janeiro: José Olympio, 1974.

SCHWARCZ, Lilia Moritz; STARLING, Heloisa Murgel. Brasil: uma biografia. São Paulo: Companhia das Letras, 2015, p. 32.

VELOSO, F.; VILLELA, A.; GIAMBIAGI, F. "Determinantes do 'Milagre' Econômico Brasileiro (19681973): Uma Análise Empírica”. Revista Brasileira de Economia, v. 62, n. 2, 2008. 